\title{
Assessment of the Potential Use of Shallow Geothermal Energy Source for Air Heating and Cooling in the Kingdom of Saudi Arabia
}

\author{
M. Ouzzane*, M. T. Naqash ${ }^{* \dagger}$ and O. Harireche* \\ *Faculty of Engineering, Islamic University in Madinah, Islamic University of Medina, Medina, P.O. Box: 170, \\ Kingdom of Saudi Arabia \\ †Corresponding author: M. T. Naqash; tayyab@iu.edu.sa, engr.tayyabnaqash@gmail.com
}

Nat. Env. \& Poll. Tech. Website: www.neptjournal.com

Received: 18-04-2021

Revised: 27-06-2021

Accepted: 14-07-2021

Key Words:

Ground temperature profile

Geothermal energy

Canadian well

Earth-air heat exchanger

\begin{abstract}
A large part of the total energy consumption in buildings in the Kingdom of Saudi Arabia (K.S.A.), is devoted to air cooling. This leads to high electricity costs for residents and a high amount of equivalent $\mathrm{CO}_{2}$ emissions. The work presented in this paper aims at evaluating and applying shallow geothermal energy for cooling and heating to reduce cost and environmental issues in the Kingdom. The system is based on the earth-air heat exchanger (EAHE) equipped with an air circulation fan. In this study, six cities have been selected; Madinah city, where our university is located, and five other cities representing five different climatic zones. A new parameter called "geothermal percentage" is proposed to calculate the ratio of geothermal energy to the cooling/heating total load. It has been shown that the proposed system covers part of the cooling load and the total heating needs for almost all the country's territory. However, both heating and cooling needs can be fulfilled by the EAHE for few cities such as Guriiat and Khamis, characterized by a moderate climate.
\end{abstract}

\section{INTRODUCTION}

Due to the global warming phenomenon, environmental scientists and international researchers are becoming more worried about the environment. Actions must be taken quite urgently to find solutions to reduce the emission of Greenhouse Gases (GHG) that are causing this problem. Many sectors are concerned about this issue (transportation, industry, residential and institutional), and many efforts have been made by promoting renewable energy and increasing energy efficiency. In buildings, air heating and cooling present an essential part of the total energy consumption, especially in cold and hot climates. Among the potential solutions for using environmentally friendly energy sources in air conditioning, shallow geothermal energy constitutes an interesting option to replace or be used alongside conventional energy systems. The simplest way to exploit geothermal energy is to use an earth/air heat exchanger called "Canadian well". Many works in this field have been conducted during the last decade (Liang 2020, Kazemiani-Najafabadi \& Amiri Rad, 2020, Dalla Longa 2020).

Al-Ajmi et al. (2006) conducted a theoretical work on building air cooling using Canadian well technology. It has been shown that, during the peak summer season, the proposed system can contribute to reducing the cooling load by $30 \%$ for a typical house. Thiers et al. (2012) developed a mathematical model for the simulation of earth/air heat exchangers considering all the parameters and phenomena of thermal exchanges except for water infiltration into the soil. The computing module used in this model is currently integrated with a software called "COMFIE". Bisoniya et al. (2013) and Yan \& Xu (2018) had published a review of theoretical and experimental works on earth-air-heat exchangers. This system alone is not sufficient to satisfy the cooling and heating all the year. However, they can preheat/precool the air to increase the energy efficiency of the conventional air conditioning system. Benhammou \& Draoui (2015) and Benhammou et al. ( 2017) applied their theoretical model to the Algerian Sahara climate (hot and arid) to predict the performance of cooling earth-to-air heat exchanger for different geometrical and operational parameters. They have shown that in transient conditions, the efficiency of the EAHE is more affected by the duration of operation, pipe diameter, and air velocity. Because of the high cooling loads, they have recommended insulating the building well and choosing a material with good thermal properties. Ghaith \& Razzaq (2018) studied the performance and the environmental impact of a hybrid system conventional/EAHE. It was shown that this proposed system can reduce the annual energy and carbon emissions by $11 \%$ compared with the conventional system. Benrachi (2020) proposed a new spiral-shaped configuration of EAHE for air cooling in a hot and arid region in Algeria. By using a commercial C.F.D. Software "ANSYS", had conducted an EAHE parametric effect on the 
system's performance (C.O.P.). It was shown that this new configuration permits the reduction of the land size of the geothermal system. Recently, Wei et al. (2021) performed an experimental study on two similar buildings. One of the two buildings was equipped with EAHE. The results showed that the EAHE system reduce the ambient air temperature by $9.12^{\circ} \mathrm{C}$ during summer and increases the ambient air by $5.53^{\circ} \mathrm{C}$ during winter (Yueer et al. 2013, Wang \& He 2014).

The Kingdom of Saudi Arabia is characterized by a long cooling season, which leads to high energy consumption by air conditioning systems. This energy presents around 50\% of the total energy consumption in the residential sector alone (Albogami \& Boukhanouf 2019). However, most of the HVAC systems used are based on the mechanical compression principle. In this system, the heat energy released to the ambient outdoor air through the condenser is higher than the cooling capacity produced in indoor air. This means that this system is contributing more to heating the external environment. On the other side, the main electrical energy source in K.S.A. is generated from power plants based on natural gas combustion. Its efficiency is low (around 30\% of the total consumed energy), which results in high greenhouse gas emissions and pollution. In addition to the environmental context, in K.S.A., the cost of electricity has tripled during the last few years. As a result, the cooling electricity bill becomes difficult for the population's middle class to afford.

The primary purpose of the present work is to reduce electricity consumption (electricity bill) and GHG emission by proposing a shallow geothermal energy source. Unfortunately, in K.S.A., the exploitation of this source of clean energy is almost non-existent. This study shows the potential of using the EAHE for air cooling/heating in many big cities in K.S.A., selected from different climatic zones.

\section{Climatic Zones and Selected Cities}

Saudi Arabia has a vast desert characterized by a long summer season with a high daily temperature and a significant drop in temperature during the night. This arid climate has a deficient annual rainfall. However, the K.S.A. has a western and eastern coast on the Persian Gulf and red sea, respectively, with higher annual relative humidity. According to the Saudi Building Code (SBC-602E) (The Saudi Building Code National Committee 2007), three different climatic zones have been identified. However, this classification does not consider differences due to the presence of sea that results in high humidity. In 2015, Alrashed \& Asif (2015) investigated more than 16 scientific models of climatic classification to propose the appropriate energy studies in a building. The authors developed and applied specific criteria to the mentioned methods to propose five climatic zones without considering the Empty Quarter region. The colored map in Fig. 1 presents the results. These zones are characterized by hot/cold dry desert subzone, hot-dry with a maritime/maritime desert subzone, and subtropical with a Mediterranean subzone and a mountainous subtype. Five cities from the above five climatic zones plus Madinah city have been selected in this study (see Table 1). The purposes of choosing Madinah city are:

- Location of University,

- Need for information and technical results for planned experimental work.

\section{Ground Temperature}

Earth is a vast solar collector that absorbs about half of the incident solar radiation. Its surface exchanges heat with the air and sky. Depending on the air ambient temperature, the ground surface loses or gains heat by convection. However, since the sky temperature is always very low, the ground surface loses heat to the sky by longwave radiation. Applying the heat energy balance on the ground surface will result in a heat flux driven by conduction in the soil. The typical ground temperature profile is characterized by two different parts, as shown in Fig. 2,

a) from the ground surface to $4 \mathrm{~m}$ depth, a high-temperature gradient is observed, and

b) from $4 \mathrm{~m}$ to about $11 \mathrm{~m}$ depth, the temperature change is damped. The temperature remains constant throughout the year, providing a warm water source and a cold source in summer.

These depths depend on the local soil properties and climate. The constant temperature of $9^{\circ} \mathrm{C}$ is called "undisturbed ground temperature" (Fig. 2).

\section{Undisturbed Ground Temperature $\mathbf{T}_{\mathrm{g}}$}

The undisturbed ground temperature (U.G.T.) represents the primary indicator of the potential of shallow geothermal sources based on which engineers perform the preliminary

Table 1. Selected cities and location coordinates.

\begin{tabular}{|lllllll|}
\hline City & Madinah & Riyadh & Guriat & Khamis & Jeddah \\
\hline Latitude & $24.5^{\circ} \mathrm{N}$ & $24.7^{\circ} \mathrm{N}$ & $31.4^{\circ} \mathrm{N}$ & $18.3^{\circ} \mathrm{N}$ & $21.5^{\circ} \mathrm{N}$ & $26.2^{\circ} \mathrm{N}$ \\
Longitude & $39.5^{\circ} \mathrm{E}$ & $46.7^{\circ} \mathrm{E}$ & $37.3^{\circ} \mathrm{E}$ & $42.8^{\circ} \mathrm{E}$ & $39.2^{\circ} \mathrm{E}$ & $50.0^{\circ} \mathrm{E}$ \\
\hline
\end{tabular}




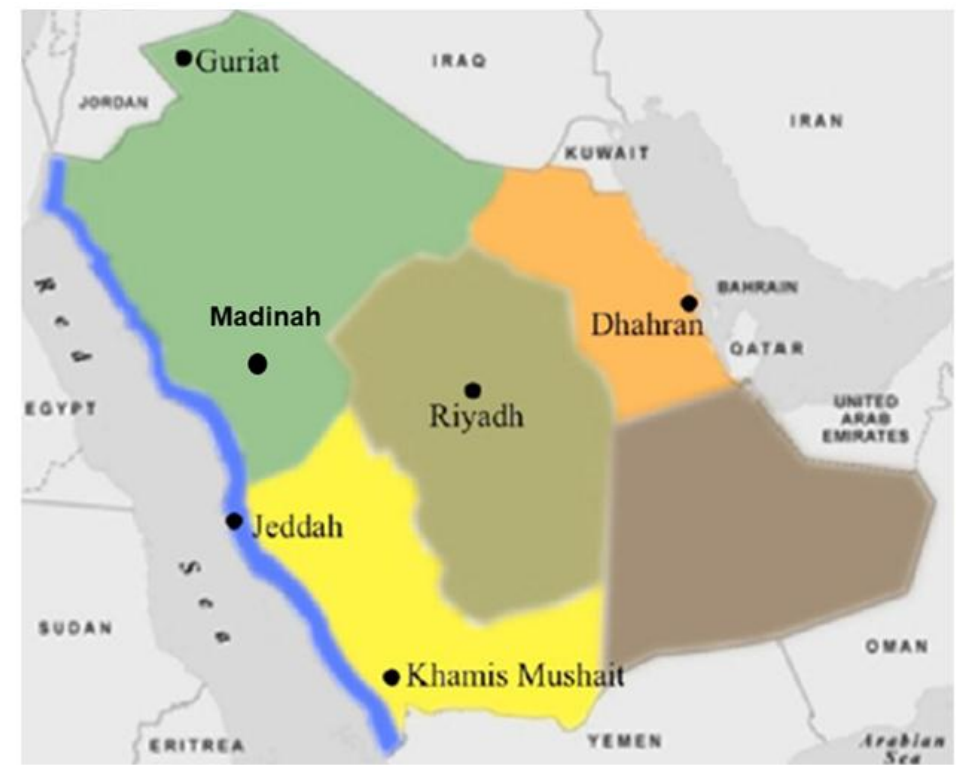

Hot-Dry Maritime subzone

Cold-Dry with a Desert subzone

Hot-Dry with a Desert subzone

Hot-Dry with a Maritime Desert subzone

Subtropical with a Mediterranean subzone and a Mountainous subtype

Empty Quarter

Fig. 1: Climatic zones in K.S.A.

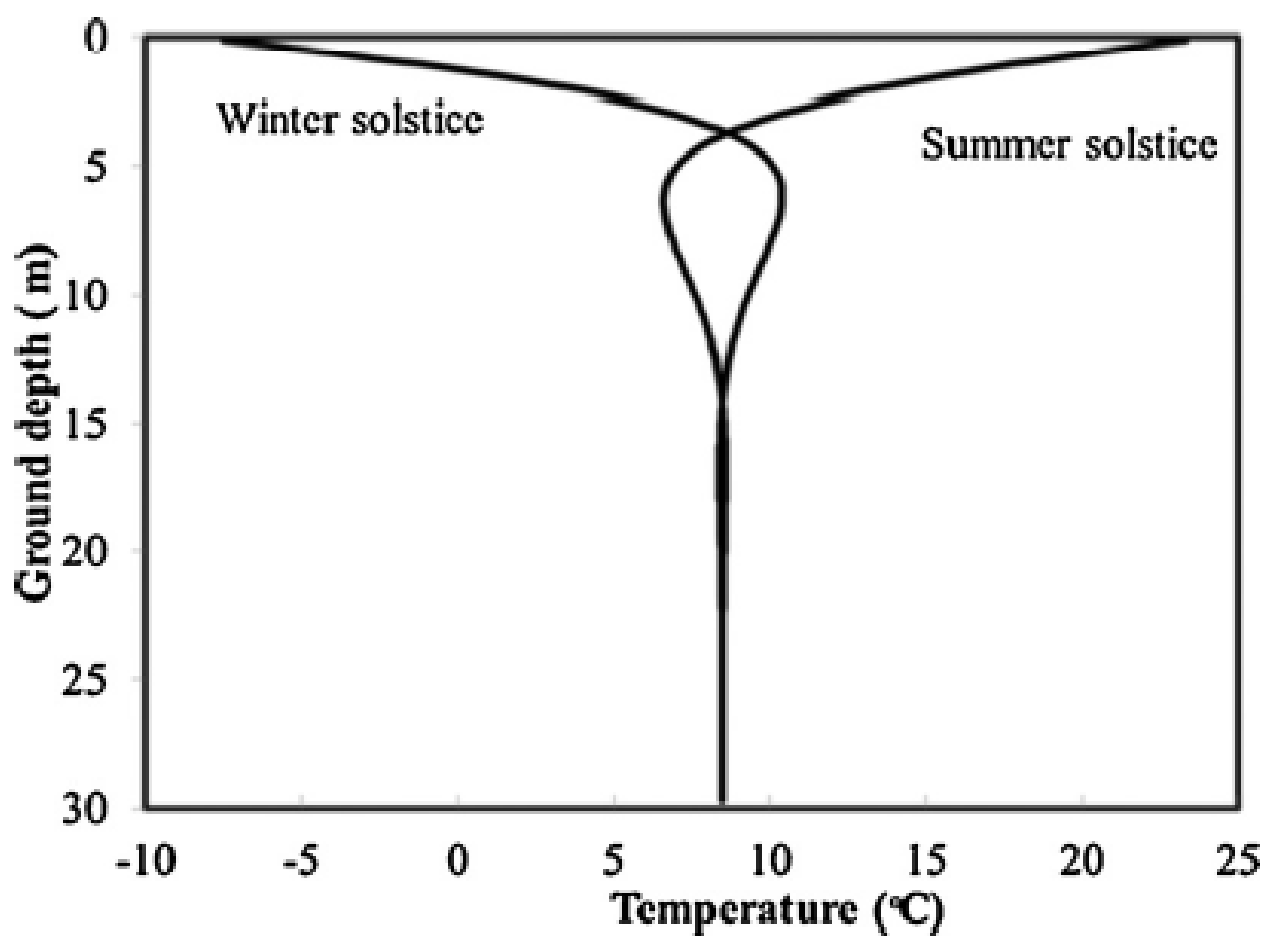

Fig. 2: Typical ground temperature. 
design of their geothermal systems. For a large shared geothermal field used for heating and cooling with a ground source heat pump, one well is used to conduct a Thermal Response Test (TRT). This test provides the value of the undisturbed ground temperature, the diffusivity and thermal conductivity of the soil, and the geological structure of different layers of the soil. Based on TRT reports of seventeen sites covering a wide range of climates; from the cold climate in Alert (Nunavut, Canada, Latitude $=82.5^{\circ} \mathrm{N}$ ) to hot climate in Dahran (Saudi Arabia, Latitude $=26.28{ }^{0} \mathrm{~N}$ ), Ouzzane (2015) developed a simple correlation between the U.G.T. and the long-term yearly average ambient temperature given by Equation (1):

$$
\mathrm{Tg}=0.9513 \times \mathrm{T}_{\mathrm{amb}}+17.898
$$

$\mathrm{T}_{\mathrm{amb}}$ and $\mathrm{T}_{\mathrm{g}}$ are in Kelvin.

Equation (1) has been used to generate U.G.T. for different cities of the Kingdom (more than 70 cities), and isotherms have been plotted on the map of the country (Fig. 3). The U.G.T. ranges from $21^{\circ} \mathrm{C}$ to $32^{\circ} \mathrm{C}$, which presents possibilities for air cooling and heating. This information helps engineers and researchers to perform a feasibility study to apply ground source heat pumps for cooling and heating.

\section{Ground Temperature Profile}

The variation of the soil temperature with depth presents a profile as shown in Fig. 2. Due to the high thermal inertia of the soil, the diurnal and seasonal air temperatures are damped along the soil's depth. This profile is characterized by the cosine wave and exponential function described by Equation (2), proposed by Kasuda and Archenbach (Kusuda \& Archenbach 1965). Several commercial software such as RETScreen (Natural Resources Canada 2013) and TRNSYS (Solar Energy Laboratory 2012) have implemented this Equation for their calculations related to the ground source heat pumps. However, for the boundary condition on the ground surface, the air ambient temperature profile is applied, which affects the accuracy of the results.

$\mathrm{T}(y, t)=\overline{\mathrm{T}}_{m}-\mathrm{A}_{s} \exp ^{-\frac{y}{\delta}} \cos \left(\omega t-\Phi_{s}-\frac{y}{\delta}\right)$

Where:

$y(\mathrm{~m})$ is the depth of the soil from the surface of the ground $(y=0)$.

$\mathrm{T}(y, t)\left({ }^{\circ} \mathrm{C}\right)$ is the soil temperature at time $t$ (days) and depth $y(\mathrm{~m})$.

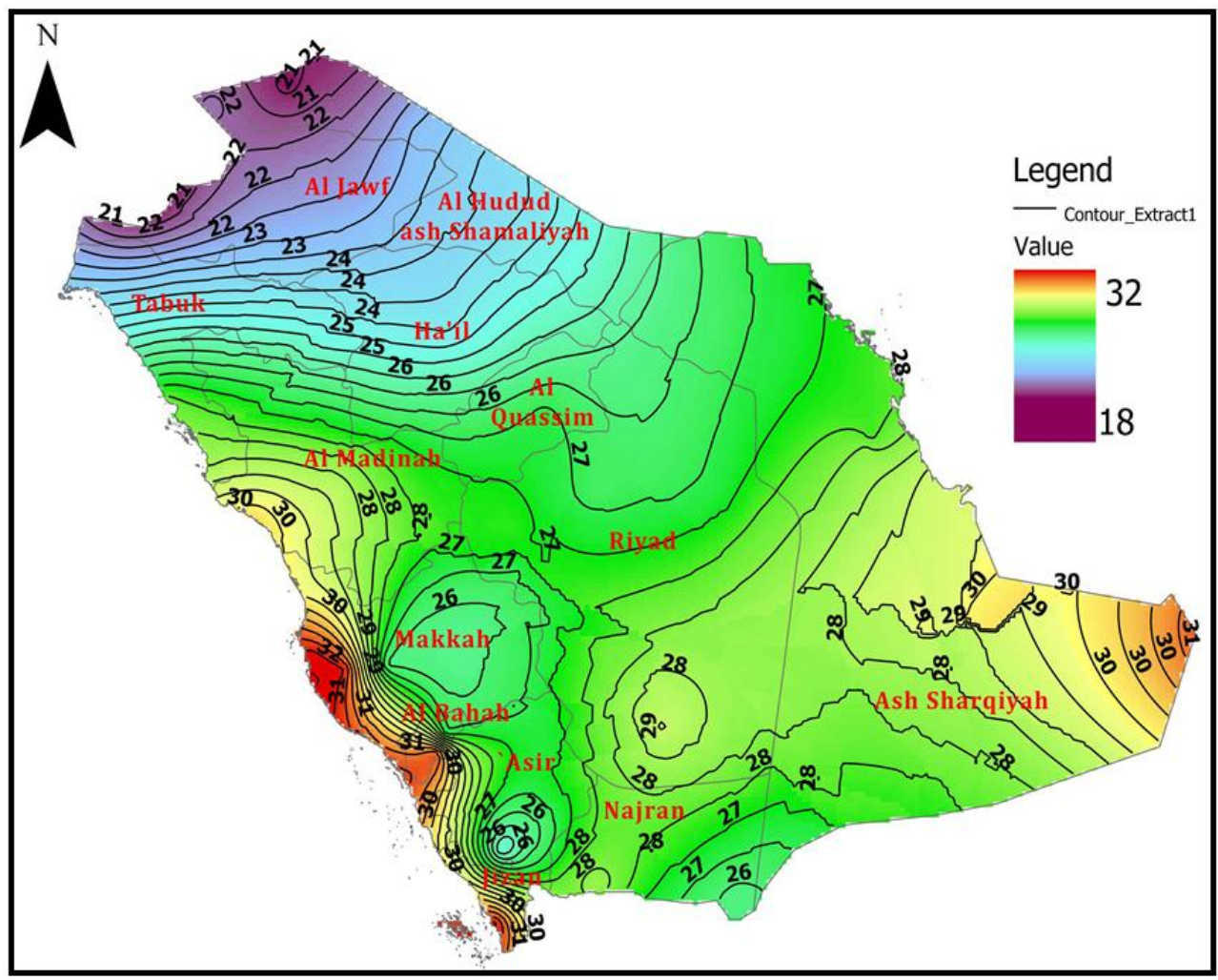

Fig. 3: Isotherms of the undisturbed ground temperature for K.S.A. 
$\overline{\mathrm{T}}_{\mathrm{m}}\left({ }^{\circ} \mathrm{C}\right)$ is the annual average ground surface temperature.

$\mathrm{A}_{\mathrm{s}}\left({ }^{\circ} \mathrm{C}\right)$ is the annual amplitude of the soil surface temperature.

$\delta$ is the damping depth (m) of annual fluctuation of the ground temperature given by Equation (3):

$$
\delta=\sqrt{\frac{2 a}{\omega}}
$$

$\omega$ is the angular frequency: $\omega=2 x \alpha / 365$.

$\Phi_{\mathrm{s}}$ is the phase angle (radian).

The ground temperature profile for Madinah city is shown in Fig. 4 and Fig. 5. The main parameters in Equation (2) are calculated using the model proposed by Badache (2016). This model consists of a new approach to improve the determination of the ground temperature profile and is based on a Fourier series approximation for sky temperature, ambient temperature, and global solar radiation on a horizontal surface. The annual amplitude $A_{s}$ and the phase angle $F_{s}$ are calculated using Equation (4) and Equation (5), respectively. The thermal properties of the soil chosen for Madinah are typical of arid soil.

$A_{s}=\left\|\frac{h_{r} \bar{A}_{a}+\alpha_{g} \bar{A}_{G} e^{i\left(\varphi_{G}-\varphi_{a}\right)}+h_{r a d} \bar{A}_{s k y} e^{i\left(\varphi_{s k y}-\varphi_{a}\right)}}{\left(h_{e}+k_{s} \delta^{\prime}\right)}\right\|$

$\varphi_{\mathrm{s}}-\varphi_{\mathrm{a}}=\operatorname{Arg}\left[\frac{\mathrm{h}_{\mathrm{r}} \overline{\mathrm{A}}_{\mathrm{a}}+\alpha_{\mathrm{G}} \overline{\mathrm{A}}_{\mathrm{G}} \mathrm{e}^{\mathrm{i}\left(\varphi_{\mathrm{G}}-\varphi_{\mathrm{a}}\right)}+\mathrm{h}_{\mathrm{rad}} \overline{\mathrm{A}}_{\text {sky }} \mathrm{e}^{\mathrm{i}\left(\varphi_{\text {sky }}-\varphi_{\mathrm{a}}\right)}}{\left(\mathrm{h}_{\mathrm{e}}+\mathrm{k}_{\mathrm{s}} \delta^{\prime}\right)}\right]$

Where

$h_{r}=h_{\text {conv }}\left(1+\right.$ c. a. f. $\left.H_{R}\right)$ and $h_{e}=h_{\text {conv }}(1+$ c. a. $f)+h_{\text {rad }}$

$\mathrm{H}_{\mathrm{r}}$ is the ambient relative humidity.

$\mathrm{a}, \mathrm{c}$ and $\mathrm{f}$ are constants; $\mathrm{a}=103(\mathrm{~Pa} / \mathrm{K}), \mathrm{c}=0.0168(\mathrm{~K} / \mathrm{Pa})$

$\mathrm{f}=1$ (saturated soil), $\mathrm{f}=0.6$ to 0.8 (moist soil)

$\mathrm{f}=0.4$ to 0.5 (dry soil) and $\mathrm{f}=0.1$ to 0.2 (arid soil)

$\alpha_{\mathrm{g}}$ absorption coefficient of the ground surface.

$\mathrm{h}_{\mathrm{rad}}$ linearized radiation heat transfer coefficient $\left(\mathrm{W} / \mathrm{m}^{2} . \mathrm{K}\right)$.

$\delta$ ' is the $\mathrm{n}^{\text {th }}$ harmonic damping depth.

Meteorological data for one representative year obtained from a long-term duration (Natural Resources Canada 2013) and (Medina, Saudi Arabia Weather Conditions | Weather Underground, no date) have been used for this work.

The typical ground temperature for Madinah is well reflected in Fig. 4 and Fig. 5. In Fig. 4, the value of U.G.T. is around $31^{\circ} \mathrm{C}$, located from 10 meters depth. On the other hand, the annual temperature amplitude at the ground surface $(\mathrm{z}=0 \mathrm{~m})$ in Fig. 5 attenuates gradually as depth increases, reflecting the damping phenomenon due to the properties of the soil. It is presented by parameter $\delta$ and given by Equation (3).

\section{Canadian Well}

Several techniques with different configurations exploit the shallow geothermal energy source, such as ground source heat pumps (horizontal and vertical wells, direct expansion, and secondary loops) and Canadian well called earth to air heat exchanger (EAHE). The Canadian well is a technique that allows us to take advantage of the heating and cooling of the subsoil (Fig. 6). Therefore, due to its simplicity and low initial cost, especially for newly constructed buildings, it has been selected in this work. The principle is to circulate the outside air in pipes buried at a depth where the ground temperature is almost stable. Depending on the seasons, the supplied air temperature can reach $14^{\circ} \mathrm{C}$ lower/higher than the ambient temperature. The buried air pipes system and the ground constitute a heat exchanger. The effectiveness of the earth/air heat exchanger given by Equation (6) is defined as the ratio of the actual heat transfer rate for a heat exchanger to the maximum possible heat transfer rate. It depends on the air's velocity, the length and diameter of the buried pipe, the properties of the soil, air temperature at the inlet, and ground temperature.

Canadian well has been applied in many countries and investigated by many researchers and engineers. In general, this kind of system cannot fulfill alone the cooling and heating needs of comfort during the winter and the summer. It depends strongly on the climate of its location. For cold climate countries, the EAHE system can easily fulfill the cooling load during the hot season and only partly the heating load during the cold season and vice versa in hot climate countries. To remedy this insufficiency and to improve the energy efficiency, several solutions have been proposed such as:

- the combination with the conventional heat pump system (Bojić 2000),

- the combination with the heat recovery ventilation system (Lapertot 2021),

- the integration of the EAHE with the hollow core floor (Xu 2014),

Table 2: The yearly average ambient temperature and U.G.T. of the Selected cities.

\begin{tabular}{|lllllll|}
\hline City & Madinah & Riyadh & Guriat & Khamis & Jeddah & Dahran \\
\hline $\mathrm{T}_{\mathrm{amb}}\left({ }^{\circ} \mathrm{C}\right)$ & 28.4 & 25.1 & 19.8 & 18.9 & 27.9 & 25.8 \\
$\mathrm{UGT}\left({ }^{\circ} \mathrm{C}\right)$ & 31.6 & 28.5 & 23.4 & 22.6 & 31.1 & 29.1 \\
\hline
\end{tabular}




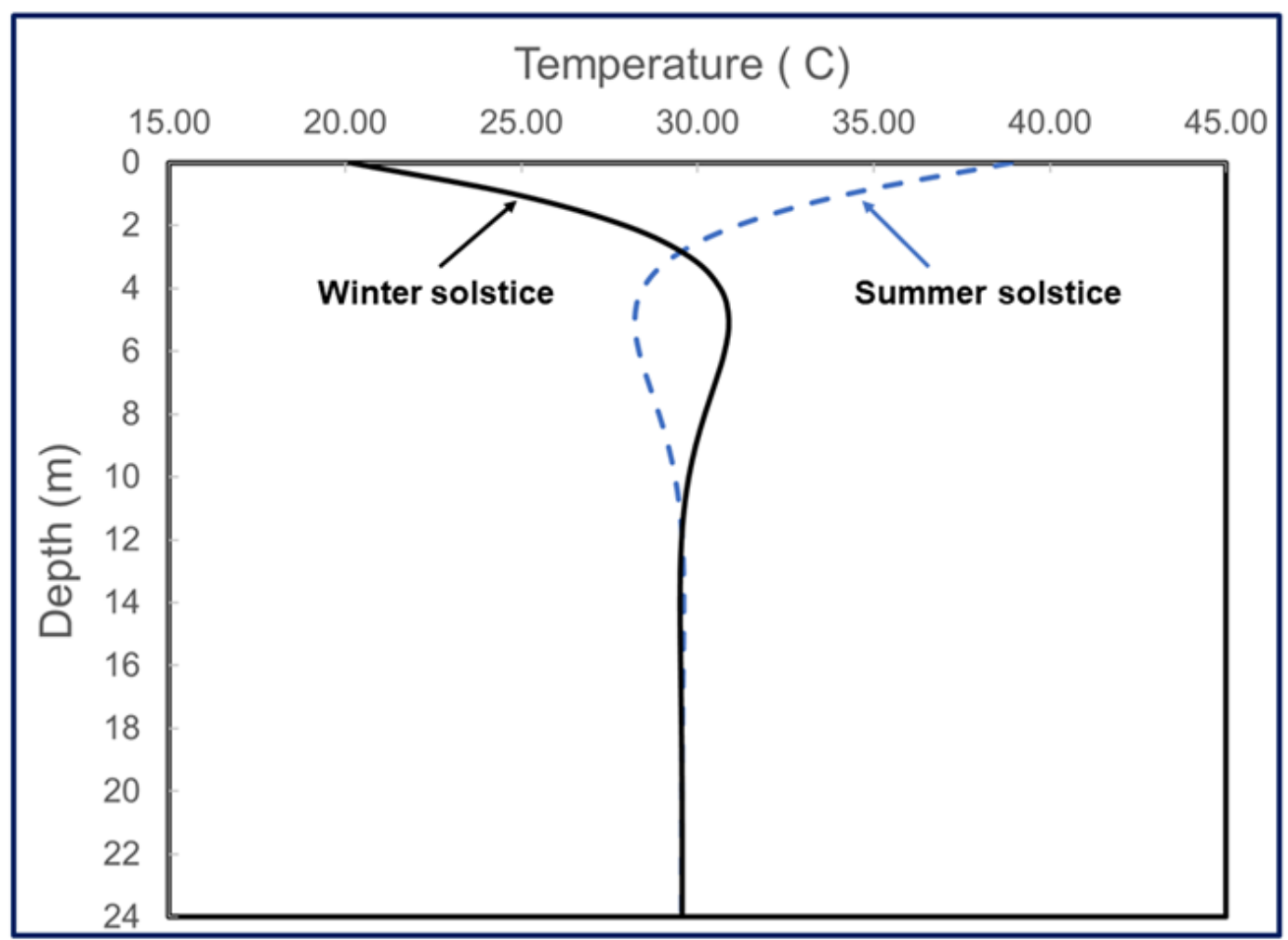

Fig. 4: Ground temperature profile for Madinah city.

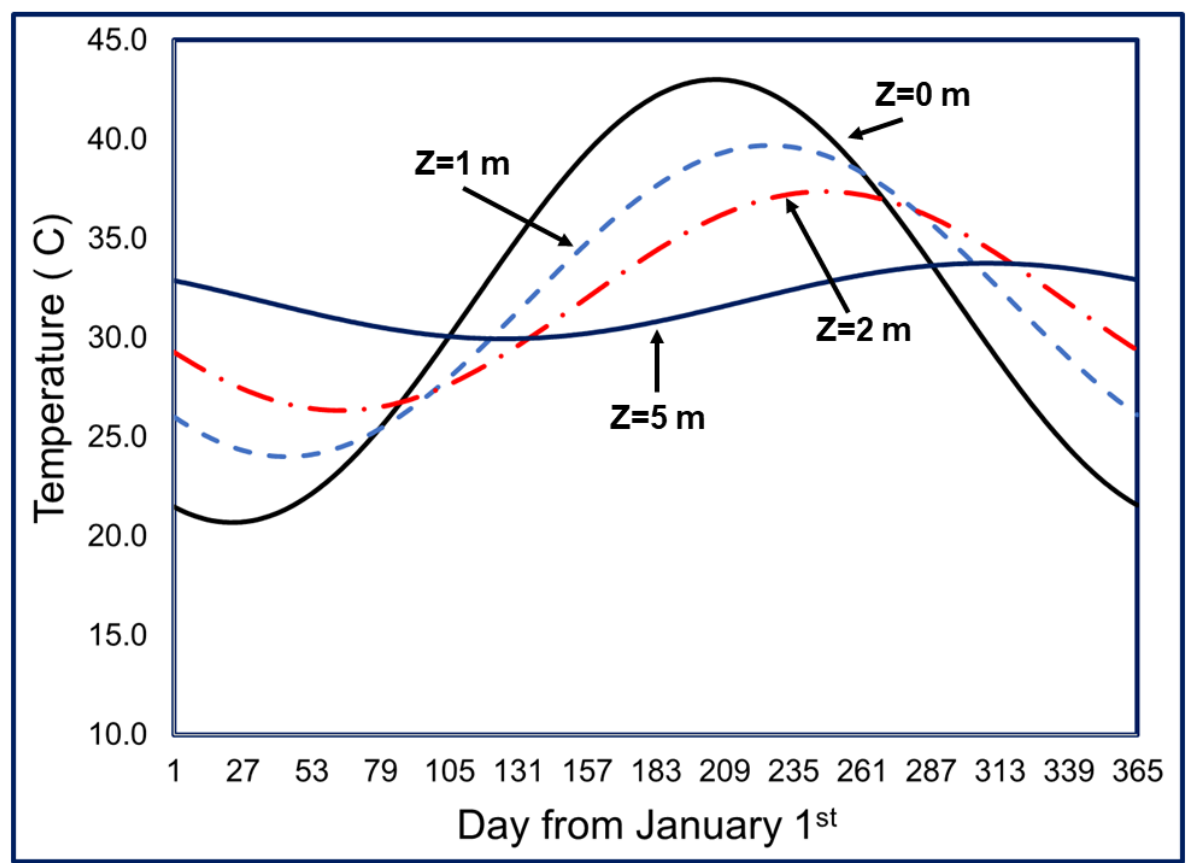

Fig. 5: Yearly variation of the soil temperature at different depths for Madinah city. 
- the integration of the EAHE with the exterior building wall which has a ventilation passage embedded inside (Yan \& Xu 2018).

The advantages of this technology are many. Some of them are summarized as a) A well-known system applied in several countries, b) Simplicity and low initial cost, especially for the new buildings, c) Use of clean energy helps to reduce pollution and the emission of greenhouse gases, d) Reduction of the energy consumption and the electricity bill as its operation practically does not require energy e) Passive system, preheating or cooling the air in a natural way.

\section{Geothermal Percentage and Analysis}

The Canadian well presented in Fig. 6 is used for cooling and heating analysis in six selected cities (Table 1) around K.S.A. The primary purpose is to know whether this system can fully or partially compensate for the heating/cooling load. To this end, a new parameter called "Geothermal Percentage" has been introduced. It is defined by the cooling/heating capacity ratio to the total cooling/heating load. The following Equation (7) provides an expression of this parameter:

In practice, the air supplied temperature must be few degrees lower/higher than the set point temperature for cooling/heating.

Fgeo-cool/heat's value ranges between 0 and 1, and the following different situations can occur.
- If $\mathrm{F}_{\text {geo-cool/heat }}=0$ (the geothermal system is not applicable) whereas,

- If $0<\mathrm{F}_{\text {geo-cool/heat }}<1$ (the geothermal system can partly fulfill the cooling/heating needs or can precool/heat the ambient air. An auxiliary energy source is needed) and

- If $\mathrm{F}_{\text {geo-cool/heat }}=1$ (the geothermal system alone can satisfy the needed cooling/heating capacity)

$\mathrm{T}_{\text {set-cool/heat }}$ is the cooling/heating indoor temperature settings for residential buildings. The Saudi building code (The Saudi Building Code National Committee 2007) recommends the following values:

- For heating mode, $\mathrm{T}_{\text {set-heat }}=20^{\circ} \mathrm{C}$

- For cooling mode, $\mathrm{T}_{\text {set-cool }}=25.5^{\circ} \mathrm{C}$

The temperature of the supplied air to the house $\mathrm{T}_{\text {ou }}$ is calculated using Equation (6) by assuming the effectiveness of the earth/air heat exchanger value $\varepsilon=0.9$. The calculations and analysis below are based on average monthly ambient temperature (Table 3) for the long term. The approach includes the different steps shown by the flowchart in Fig. 7 . The following parameters $\mathrm{T}_{\mathrm{amb}}, \mathrm{T}_{\mathrm{ou}}, \mathrm{T}_{\mathrm{g}}, \mathrm{T}_{\text {set-cool, }}$ and $\mathrm{T}_{\text {set-heat, }}$ allow judging the need for cooling or heating. It also helps to assess if the geothermal system can overcome the heating or cooling load. With this, different situations are possible:

- Case 1: If $\left(\mathrm{T}_{\mathrm{amb}}-\mathrm{T}_{\text {set-heat }}\right)<0 \quad$ (needs heating)

- Case 2: If $0<\left(\mathrm{T}_{\text {amb }}-\mathrm{T}_{\text {set-heat }}\right)<\left(\mathrm{T}_{\text {set-cool }}-\mathrm{T}_{\text {set-heat }}\right)=$

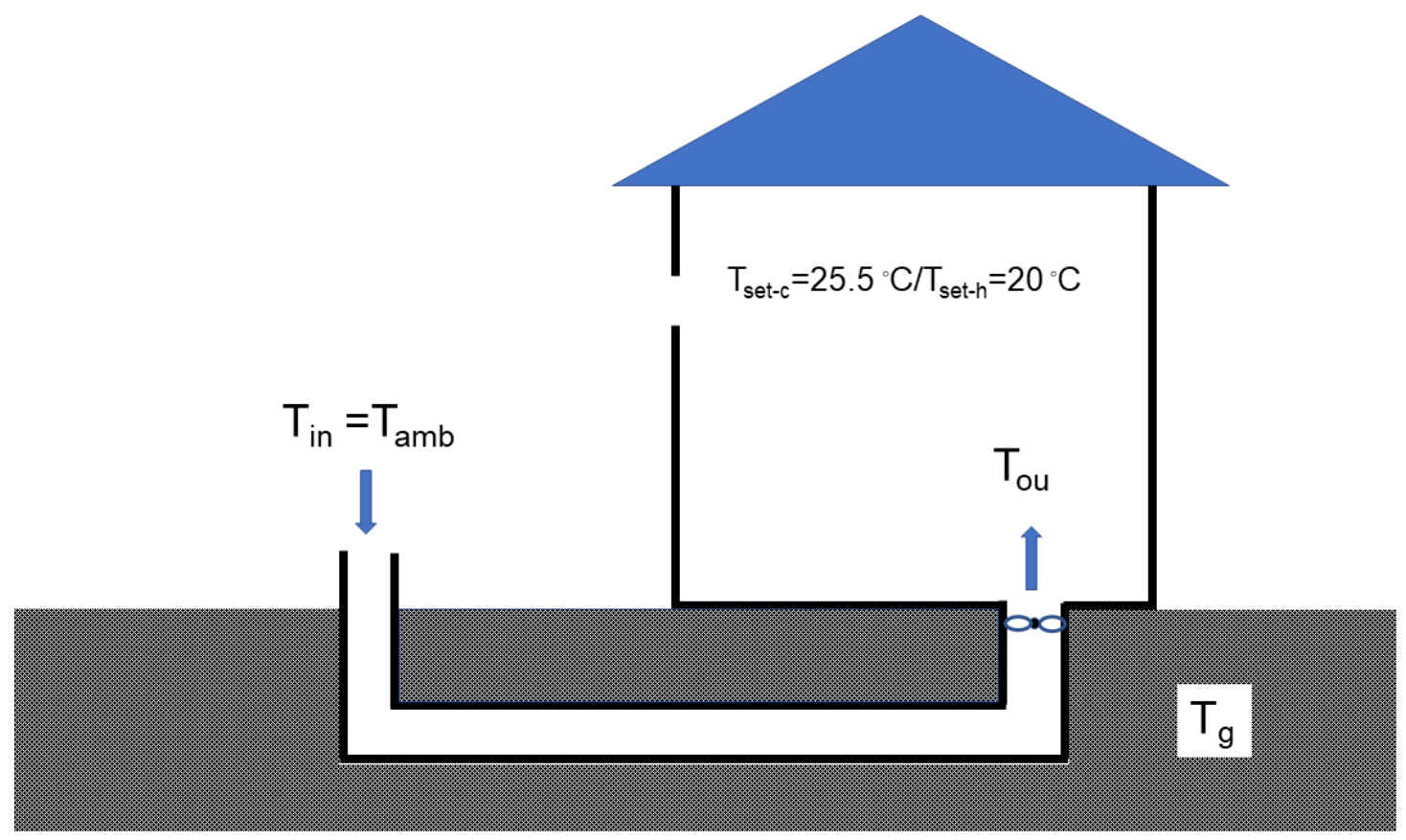

Fig. 6: Schematic representation of the Canadian well. 
$5.5^{\circ} \mathrm{C}$ (no cooling, no heating needed)

- Case 3: If $\left(\mathrm{T}_{\text {amb }}-\mathrm{T}_{\text {set-heat }}\right)>\left(\mathrm{T}_{\text {set-cool }} \mathrm{T}_{\text {set-heat }}\right)=5.5^{\circ} \mathrm{C}$ (needs cooling)

In this work, Madinah city is considered as a base case for the detailed analysis. Fig. 8 shows the monthly temperature difference between the ambient air and the supplied air to the house $\left(\mathrm{T}_{\text {in }}-\mathrm{T}_{\mathrm{ou}}\right)$. The positive values observed during the five months of the summer seasons, starting from May to September, confirmed that the ground is warmer than the ambient air. However, from October to April, the negative values mean that the ground is colder than the outside air

Table 3: Monthly average ambient temperature in $\left({ }^{\circ} \mathrm{C}\right)$.

\begin{tabular}{|lllllll|}
\hline Month & Madinah & Riyadh & Guriat & Khamis & Jeddah & Dahran \\
\hline Jan & 18.3 & 15.1 & 7.5 & 13.5 & 23.9 & 15.0 \\
Feb & 20.2 & 16.5 & 10.0 & 16.0 & 24.8 & 16.5 \\
Mar & 24.4 & 22.7 & 12.0 & 17.0 & 26.4 & 20.0 \\
Apr & 28.2 & 26.6 & 18.0 & 20.0 & 28.8 & 24.9 \\
May & 34.1 & 32.5 & 23.0 & 23.0 & 31.8 & 30.5 \\
Jun & 37.8 & 36.0 & 27.0 & 26.0 & 32.8 & 34.8 \\
Jul & 37.9 & 37.4 & 30.0 & 26.0 & 33.9 & 35.9 \\
Aug & 37.3 & 36.5 & 30.0 & 25.0 & 33.9 & 36.2 \\
Sep & 37.0 & 33.9 & 27.0 & 23.0 & 32.7 & 33.9 \\
Oct & 31.0 & 27.5 & 23.0 & 22.0 & 31.0 & 29.1 \\
Nov & 24.9 & 20.4 & 15.0 & 17.0 & 28.5 & 23.9 \\
Dec & 20.5 & 16.1 & 8.0 & 15.0 & 26.1 & 16.8 \\
\hline
\end{tabular}

N.N.: No cooling, no heating is needed.

N.W: No working.

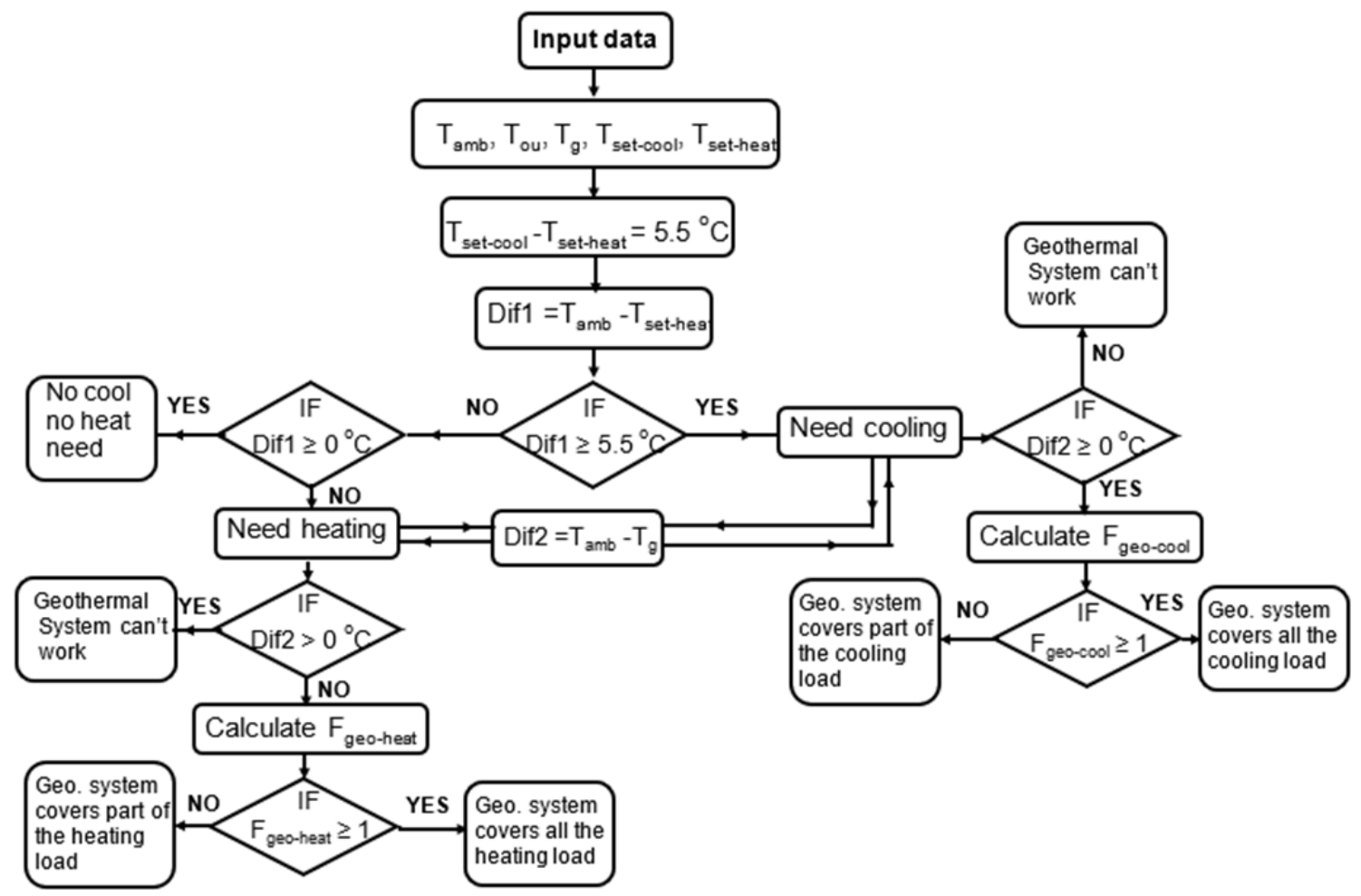

Fig. 7: Flowchart of different steps of the approach used. 


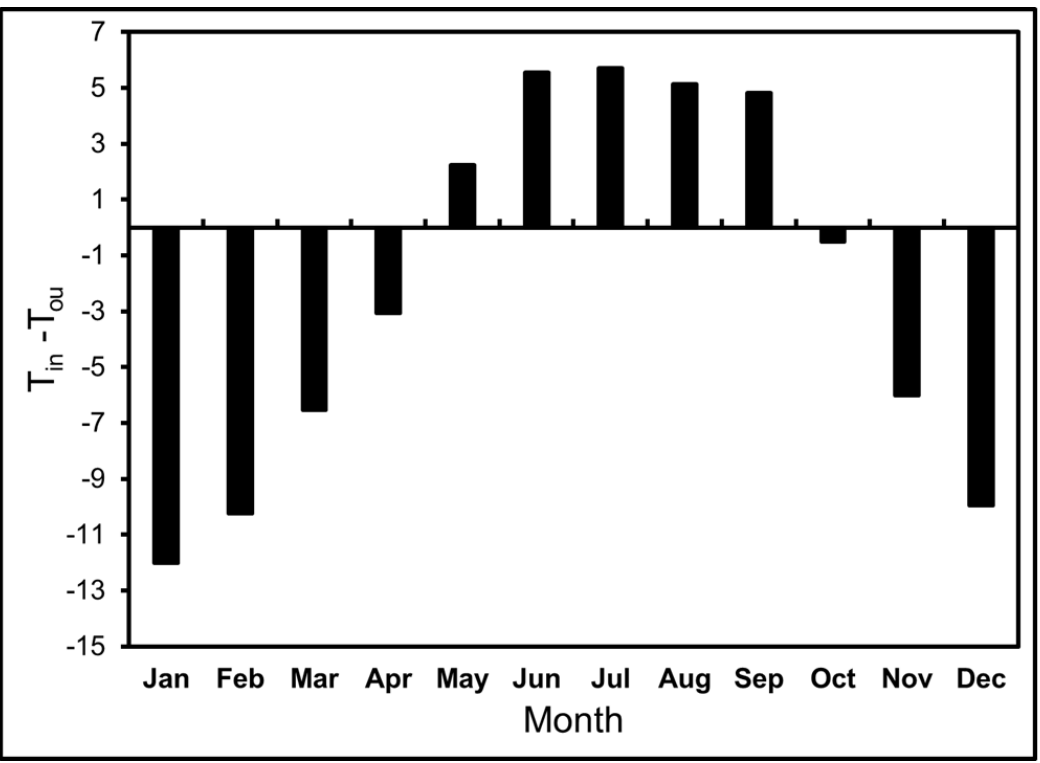

Fig. 8: The monthly temperature difference between ambient air and supplied air to the house for Madinah city.

during the remaining months. The highest absolute values in July and January reflect the highest existing potential for cooling and heating, respectively. Table 4 presents results regarding the above algorithm applied to analyze the Canadian well for heating and cooling. It illustrates that heating is only a concern in January (case 1), February, March, November, and December fall in case 2, where the climate is moderate. Hence, there is no need for cooling or heating. From April till October, the remaining months, the climate is hot, and there is a need for cooling (case 3). However, there is an exception for April and October. Therefore, the geothermal system cannot work because the ground is warmer than the ambient air. During cooling and heating periods, the geothermal percentage factor is calculated and presented in the two last columns of Table 4. For the cooling mode, the geothermal energy source can contribute $26 \%$ to $46 \%$. The remaining part should be provided from an auxiliary energy source. However, the Canadian well can fulfill all the needs $(100 \%)$.

Fig. 9 permits us to know which city has the highest potential of geothermal contribution for air cooling and

Table 4: Geothermal contribution for cooling and heating in Madinah.

\begin{tabular}{|c|c|c|c|c|c|c|c|c|}
\hline Month & $\mathrm{T}_{\mathrm{amb}}$ & $\mathrm{T}_{\mathrm{g}}$ & $\mathrm{T}_{\mathrm{ou}}$ & $\mathrm{T}_{\mathrm{amb}}-\mathrm{T}_{\text {set-heat }}$ & Need for Cool/Heat & $\mathrm{T}_{\mathrm{amb}}-\mathrm{T}_{\mathrm{ou}}$ & $\mathrm{F}_{\text {geo-cool }}$ & $\mathrm{F}_{\text {geo-heat }}$ \\
\hline Jan & 18.3 & 31.6 & 30.3 & -1.7 & Need Heat & -12.0 & $\mathrm{x}$ & $100 \%$ \\
\hline Feb & 20.2 & 31.6 & 30.5 & 0.2 & $\mathrm{NN}$ & $\mathrm{x}$ & $\mathrm{x}$ & NA \\
\hline Mar & 24.4 & 31.6 & 30.9 & 4.4 & $\mathrm{NN}$ & $\mathrm{x}$ & $\mathrm{x}$ & NA \\
\hline Apr & 28.2 & 31.6 & 31.3 & 8.2 & Need Cool but Geo N W & $\mathrm{x}$ & $\mathrm{x}$ & NA \\
\hline May & 34.1 & 31.6 & 31.8 & 14.1 & Need Cool & 2.2 & 0.26 & NA \\
\hline Jun & 37.8 & 31.6 & 32.2 & 17.8 & Need Cool & 5.5 & 0.45 & NA \\
\hline Jul & 37.9 & 31.6 & 32.2 & 17.9 & Need Cool & 5.7 & 0.46 & NA \\
\hline Aug & 37.3 & 31.6 & 32.2 & 17.3 & Need Cool & 5.1 & 0.44 & NA \\
\hline Sep & 37.0 & 31.6 & 32.1 & 17.0 & Need Cool & 4.8 & 0.42 & NA \\
\hline Oct & 31.0 & 31.6 & 31.5 & 11.0 & Need Cool but Geo N W & $\mathrm{x}$ & $\mathrm{x}$ & NA \\
\hline Nov & 24.9 & 31.6 & 30.9 & 4.9 & $\mathrm{NN}$ & $\mathrm{x}$ & $\mathrm{x}$ & NA \\
\hline Dec & 20.5 & 31.6 & 30.5 & 0.5 & $\mathrm{NN}$ & $\mathrm{x}$ & $\mathrm{x}$ & NA \\
\hline
\end{tabular}




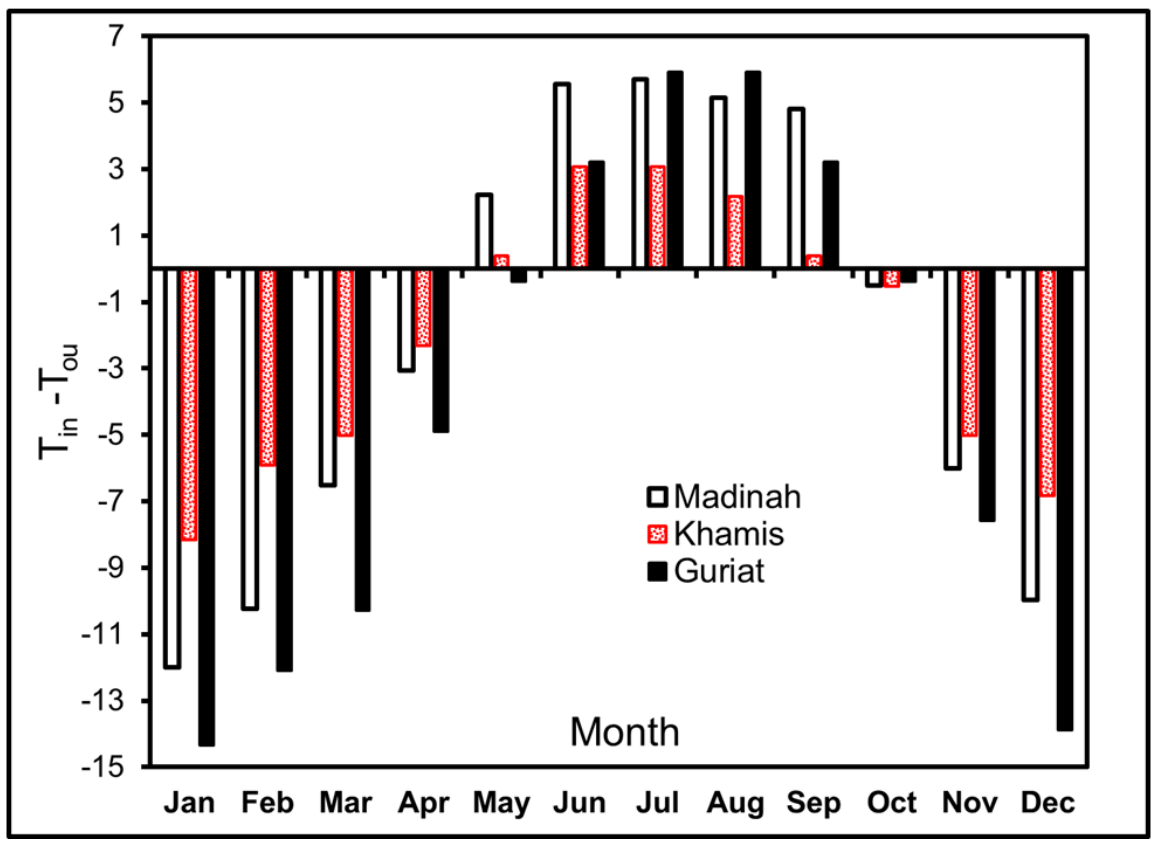

Fig. 9: The monthly temperature difference between ambient air and supplied air to the house for different cities.

heating. Here, only three cities have been chosen among the six previously selected.

Riyadh, Jeddah, and Daman cities have not been chosen; they do not show an essential difference with Madinah city. Madinah presents the highest temperature difference during the summer season and then the best geothermal potential for cooling. However, even in Madinah, with a Canadian well, heating can be provided easily. Guriat presents the highest potential for heating with a temperature difference near $-15^{\circ} \mathrm{C}$.

Table 5 and Fig. 10 show the monthly geothermal Percentage of cooling/heating for the different cities in a typical K.S.A climate dominated by hot weather results in high undisturbed ground temperature (U.G.T.) over most of the K.S.A. cities than the heating indoor temperature settings $\mathrm{T}_{\text {set-heat }}$. Consequently, the Canadian well is an appropriate technology to fulfill easily $\left(\mathrm{F}_{\text {geo-heat }}=100 \%\right)$ the heating load as presented in Table 5. However, for the cooling mode, in most of the cities, the geothermal system can provide only part of the air conditioning needed $\left(\mathrm{F}_{\text {geo-cool }}<100 \%\right)$, except for Khamis and Guriat. These two cities have a moderate climate, and the Canadian well system alone can fulfill the heating and cooling loads. Riyadh has the highest geothermal percentage in July with $\mathrm{F}_{\text {geo-cool }}=67.5 \%$, followed by
Dahran $\mathrm{F}_{\text {geo-cool }}=59.4 \%$ in August and then Madinah with $\mathrm{F}_{\text {geo-cool }}=45.9 \%$ in July. Jeddah presents the low percentage with $\mathrm{F}_{\text {geo-cool }}=29.9 \%$. Therefore, during the summer season and the Canadian well system, Madinah, Riyadh, Jeddah, and Dahran need an auxiliary energy source to satisfy the comfort in the building.

\section{CONCLUSION}

A potential assessment of the Canadian and a shallow geothermal energy source for cooling and heating in Saudi Arabia has been conducted. The study is based on monthly average ambient temperature for a long-term period in six different cities selected according to the diverse climatic zones in K.S.A. The undisturbed ground temperature has been determined for more than 70 cities and applied to generate isotherms presented on the map of K.S.A. This information is beneficial for engineers who are interested in shallow geothermal applications. In addition, a new factor has been proposed to estimate the percentage of geothermal contribution. For all cities, the shallow geothermal energy sources can easily satisfy all the heating needs and partly the cooling needs for the hottest cities as; Madinah, Jeddah, Riyadh, and Dahran. However, an auxiliary energy source must be added. 


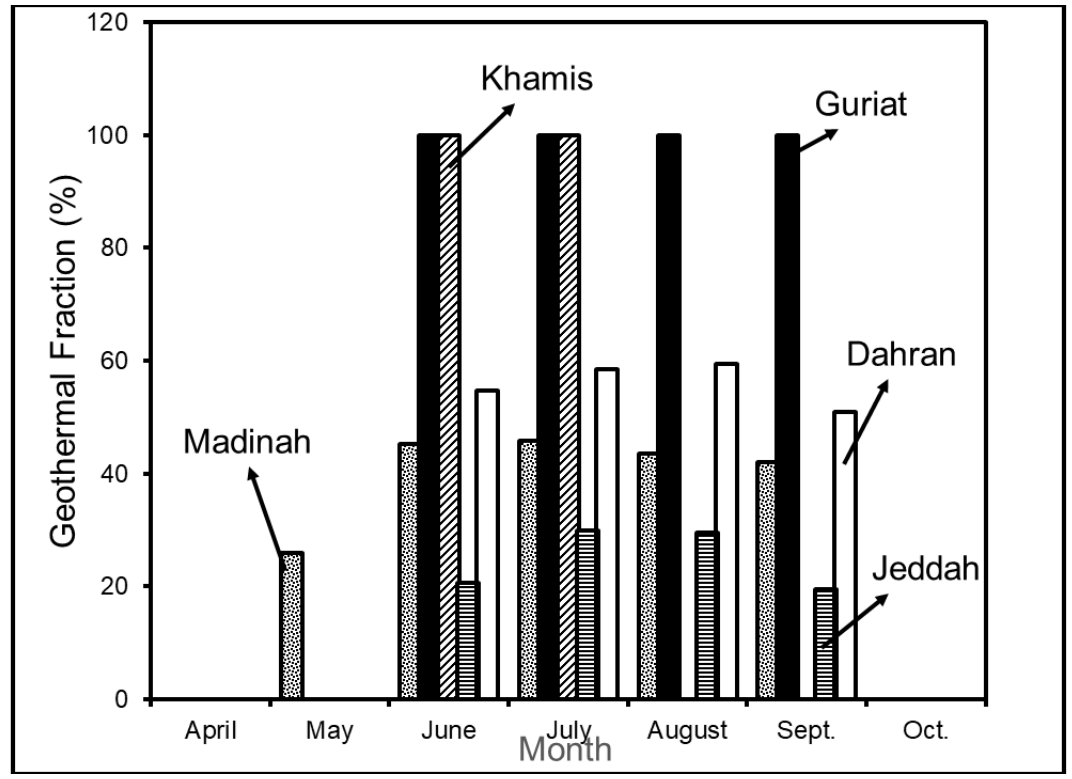

Fig. 10: Monthly geothermal percentage of cooling for different cities.

Table 5: Comparison of geothermal Percentage for different cities.

\begin{tabular}{|c|c|c|c|c|c|c|c|c|c|c|c|c|}
\hline \multirow[t]{2}{*}{ Month } & \multicolumn{2}{|c|}{ Madinah } & \multicolumn{2}{|l|}{ Riyadh } & \multicolumn{2}{|l|}{ Guriat } & \multicolumn{2}{|c|}{ Khamis } & \multicolumn{2}{|l|}{ Jeddah } & \multicolumn{2}{|c|}{ Dahran } \\
\hline & Cool & Heat & Cool & Heat & Cool & Heat & Cool & Heat & Cool & Heat & Cool & Heat \\
\hline Jan & & 100 & & 100 & & 100 & & 100 & & & & 100 \\
\hline $\mathrm{Feb}$ & & & & 100 & & 100 & & 100 & & & & 100 \\
\hline Mar & & & & & & 100 & & 100 & & & & \\
\hline Apr & & & & & & 100 & & & & & & \\
\hline May & 25.98 & & 51.58 & & & & & & & & & \\
\hline Jun & 45.24 & & 64.51 & & 100 & & 100 & & 20.61 & & 54.78 & \\
\hline Jul & 45.85 & & 67.48 & & 100 & & 100 & & 29.88 & & 58.51 & \\
\hline Aug & 43.52 & & 65.75 & & 100 & & & & 29.54 & & 59.39 & \\
\hline Sep & 42.07 & & 58.18 & & 100 & & & & 19.54 & & 51.01 & \\
\hline \multicolumn{13}{|l|}{ Oct } \\
\hline Nov & & & & & & 100 & & 100 & & & & \\
\hline Dec & & & & 100 & & 100 & & 100 & & & & \\
\hline
\end{tabular}

\section{Nomenclature}

$\begin{array}{ll}\text { A } & \text { the amplitude of the temperature, }(\mathrm{K}) \\ \mathrm{F} & \text { geothermal percentage } \\ \mathrm{h} & \text { thermal conductivity, }(\mathrm{W} / \mathrm{m} \cdot \mathrm{K}) \\ \mathrm{t} & \text { time, (days) } \\ \mathrm{T} & \text { temperature, }(\mathrm{K}) \\ \mathrm{y} & \text { depth in the ground, }(\mathrm{m})\end{array}$

\section{Greek symbols}

$\begin{array}{ll}\alpha & \text { thermal diffusivity, }\left(\mathrm{m}^{2} / \text { day }\right) \\ \alpha_{\mathrm{s}} & \text { absorption coefficient } \\ \mathrm{E} & \text { effectiveness of EAHE } \\ \delta & \text { damping depth, }(\mathrm{m}) \\ \Phi & \text { phase angle (radians) } \\ \omega & \text { angular frequency, (radians/day) }\end{array}$




\section{Subscript}

$\begin{array}{ll}\text { a, amb } & \text { ambient } \\ \text { conv } & \text { convective heat transfer } \\ \text { G } & \text { Global solar radiation on a horizontal surface } \\ \text { g } & \text { ground } \\ \text { geo-cool } & \text { geothermal cooling } \\ \text { geo-heat } & \text { geothermal heating } \\ \text { in } & \text { inlet } \\ \text { ou } & \text { outlet } \\ \text { s } & \text { ground surface } \\ \text { sky } & \text { sky } \\ \text { conv } & \text { convection }\end{array}$

\section{ACKNOWLEDGMENTS}

The authors would like to thank the Saudi Ministry of Education and the Research deanship of the Islamic University in Madinah for the funding support under Project No. 20/12.

\section{REFERENCES}

Al-Ajmi, F., Loveday, D.L. and Hanby, V.I. 2006. The cooling potential of earth-air heat exchangers for domestic buildings in a desert climate. Build. Environ., 27(1): 67-79.

Albogami, S.M. and Boukhanouf, R. 2019. Residential building energy performance evaluation for different climate zones. IOP Conf. Series: Earth Environ. Sci., 32(9): 57-80.

Alrashed, F. and Asif, M. 2015. Climatic classifications of Saudi Arabia for building energy modeling. Energy Procedia, 7: 245.

Badache, M. 2016. A new modeling approach for improved ground temperature profile determination. Renew. Energy, 6: 20.

Benhammou, M. and Draoui, B. 2015. Parametric study on the thermal performance of earth-to-air heat exchanger used for cooling of buildings. Renew. Sustain. Energy Rev., 12: 14-30.

Benhammou, M., Draoui, B. and Hamouda, M. 2017. Improvement of the summer cooling induced by an earth-to-air heat exchanger integrated into a residential building under a hot and arid climate. Appl. Energy, 12: 212-239.

Benrachi, N. 2020. Numerical parametric study of a new earth-air heat exchanger configuration designed for hot and arid climates. Int. J. Green Energy, 17: 121-156.
Bisoniya, T.S., Kumar, A. and Baredar, P. 2013. Experimental and analytical studies of earth-air heat exchanger (EAHE) systems in India: A review. Renew. Sustain. Energy Rev., 11: 23.

Bojić, M. 2000. Optimization of heating and cooling of a building by employing refuse and renewable energy. Renew. Energy, 6: 117-122.

Dalla Longa, F. 2020. Scenarios for geothermal energy deployment in Europe. Energy, 16: 118-126.

Ghaith, F.A. and Ur Razzaq, H. 2018. Thermal performance of earth-air heat exchanger systems for cooling applications in residential buildings. ASME International Mechanical Engineering Congress and Exposition, Proceedings (IMECE), 9-15 November 2018, Pittsburgh, Pennsylvania, USA. ASME, New York, USA, pp. 1-12.

Kazemiani-Najafabadi, P. and Amiri Rad, E. 2020. Optimization of an improved power cycle for geothermal applications in Iran. Energy, 11: 83-97.

Kusuda, T. and Archenbach, P. 1965. Earth temperature and thermal diffusivity at selected stations in the United States, ASHRAE Transaction.

Lapertot, A. 2021. Optimization of an earth-air heat exchanger combined with heat recovery ventilation for residential building needs. Energy Build., 10: 702-713.

Liang, J.D. 2020. Experimental investigation of a liquid desiccant dehumidification system integrated with shallow geothermal energy. Energy, 11: 52-64

Medina, Saudi Arabia Weather Conditions. n.d. Weather Underground. Available at: https://www.wunderground.com/weather/sa/medina/24.45999908,39.61999893 (Accessed: 1 March 2021).

Natural Resources Canada. 2013. RETScreen ® International. RETScreen Clean Energy Project Analysis Software.

Ouzzane, M. 2015. 'New correlations for the prediction of the undisturbed ground temperature. Geothermics, 8: 11-21

Solar Energy Laboratory. 2012. Trnsys 17. University Wisconsin-Madison, USA.

The Saudi Building Code National Committee. 2007. '601: Energy conservation requirements. Saudi Building Code, SA.

Thiers, S. 2012. Thermal modeling of an air-ground heat exchanger for building cooling. Solar Energy, 82(9): 820-831.

Wang, Z. and He, T. 2014. Influence of urban heat island on office building energy consumption. Nature Environ. Pollut. Technol., 54: 11-21.

Wei, H. 2021. Field experiments on the effects of an earth-to-air heat exchanger on the indoor thermal environment in summer and winter for a typical hot-summer and cold-winter region', Renew. Energy, 6(3): 32-47.

Xu, X. 2014. Research and application of active hollow core slabs in building systems for utilizing low energy sources. Appl. Energy, 9: 64.

Yan, T. and Xu, X. 2018. Utilization of Ground Heat Exchangers: A Review. Current Sustainable/Renewable Energy Reports.

Yueer, H., Shini, P. and Meng, L. 2013. Impact analysis on the energy-saving and land-saving properties of green buildings with different per capita floor space of residential buildings. Nature Environ. Pollut. Technol., 5: 717 